\title{
A Dynamical Study of a Rotor Supported by a Radial Journal Bearing Incorporating a Spherical Squeeze Film Damper
}

Khảo sát động lực học của một hệ trục đỡ bởi ổ trượt có tích hợp giảm chấn SFD lòng cầu

\author{
Pham Minh Hai", Nguyen Xuan Ha, Nguyen Minh Quan \\ Hanoi University of Science and Technology, Hanoi, Vietnam \\ *Email: hai.phamminh1@hust.edu.vn
}

\begin{abstract}
The reduction of noises, vibration, and mechanical waves transmitting through water from the shells of submarines is essential to their safe operation and travelling. Vibrations from the rotors of the engines are widely deemed as one of the main sources to which engineers have tried to attenuate with various designs. Squeeze-film dampers can be easily integrated into rotor-bearing structures in order to lower the level of vibrations caused by rotors out of balance. For this advantage, squeeze-film dampers are widely used in airturbine engines. This paper presents preliminary results of a numerical simulation of a shaft running on a journal bearing integrated with a squeeze-film damper and evaluates the capacity in reducing vibrations concerning the stability of static equilibrium of the shaft journal center. The proposed damper is designed in spherical shape with self-aligning capacity. The results were obtained using finite difference method and numerical integration of the full nonlinear equations of motion.
\end{abstract}

Keywords: Vibrations, noise, squeeze-film damper, rotor-dynamics, nonlinear bearings, submarines.

Tóm tắt

Giảm rung động, tiếng ồn và sóng cơ học truyền từ vỏ tàu ngầm truyền ra môi trường nước có vai trò quan trọng đối với sự an toàn trong vận hành và di chuyển của tàu. Các rung động từ trục quay của các động co thường được xem là một trong những nguyên nhân chính, cái mà các nhà thiết kế đã tìm nhiều giải pháp khác nhau để khống chế. Giảm chấn màng-ép (SFD) có kết cấu đơn giản nên có thể dễ dàng tích hợp vào kết cấu các gối đỡ trục để hạn chế rung động gây ra từ sự mất cân bằng trục. Giảm chấn SFD được sử dụng phổ biến trong các kết cấu động cơ máy bay kiểu tuốc bin khí. Bài báo này trình bày những kết quả mô phỏng động lực học của hệ trục-ổ trượt-giảm chấn màng ép-gối đỡ và đánh giá sơ bộ về khả năng giảm rung và tiếng ồn trên vỏ tàu ngầm cỡ nhỏ, với giảm chấn màng ép có kết cấu kiểu lòng cầu để tăng tính tự lựa khi tích hợp với ổ trượt. Kết quả tính toán mô phỏng thu được nhờ sử dụng phương pháp sai phân hữu hạn và giải các phương trình vi phân chuyển động phi tuyến bằng phương pháp số.

Từ khóa: Rung động, tiếng ồn, giảm chấn SFD, động lực học trục, ổ đỡ phi tuyến, tàu ngầm.

\section{Introduction}

Squeeze film damper (SFD) is widely used in gas turbine engines to protect the machine against the effects of vibrations caused by shaft unbalance and other causes. With a simple structure and easy integration with bearings in aircraft engines [1-3], air compressors, etc., SFDs have been used to reduce vibrations when engines run through their resonant regions and at the same time limit the force transmitted through the body [4-7].

The research and manufacture of small submarines in Vietnam have been attracting the attention and efforts of researchers, scientists, etc. For submarines, the design requirements in minimizing the noise and sound waves propagating into the aquatic environment [8-9] are necessary. One of the measures that designers can think of is to suppress or reduce the source of vibration.
SFDs have normally been integrated into rollingelement bearings instead of journal bearings. One of the reasons is that journal bearings provide a certain amount of damping capacity to prevent shocks and dissipate external sources of vibrations. However, journal bearings can become the source of self-excited stimulation leading to instability of the whole system.

This paper aims to use the advantages of SFDs to reduce vibration for shafts such as used in submarines which are supported by journal bearings.

\section{Modelling of Shaft-Bearing Systems}

\subsection{Shaft-Conventional Journal Bearing}

The first rotor-bearing system being considered is a rotor running on conventional journal bearing. The shaft journal and the housing surfaces are cylindrical. The small gap between the two surfaces is filled with pressurized lubricating oil by a pump. The diagram of

ISSN 2734-9381

https://doi.org/10.51316/jst.154.etsd.2021.31.5.2

Received: November 28, 2016; accepted: October 25, 2021 
a shaft support system using a journal bearing can be shown in Fig. 1.

The equation of motion of the rotordynamic system shown in Fig. 1 can be written as follows:

$$
\left[\begin{array}{cc}
m_{\mathrm{t}} & 0 \\
0 & m_{\mathrm{t}}
\end{array}\right]\left(\begin{array}{l}
x_{\mathrm{t}} \\
\cdot \\
y_{\mathrm{t}}
\end{array}\right)=\left(\begin{array}{l}
f_{\mathrm{b}}^{(x)} \\
f_{\mathrm{b}}^{(y)}
\end{array}\right)+\left(\begin{array}{c}
0 \\
S_{\mathrm{t}}
\end{array}\right)
$$

where $x_{\mathrm{t}}$ and $y_{\mathrm{t}}$ are the displacements of the shaft center relative to the center of the bearing which is fixed on the machine body; $m_{\mathrm{t}}$ is the effective mass of the shaft at the center of the journal; $S_{\mathrm{t}}=g m_{\mathrm{t}}$ is the static external force acting on the shaft in the $y$ direction; $f_{\mathrm{b}}^{(x)}$ and $f_{\mathrm{b}}^{(y)}$ are the total oil film pressure acting on the journal in the $x$ and $y$ directions, respectively (see 2.3).

\subsection{Shaft-Journal Bearing-Spherical SFD}

Fig. 2 depicts the shaft system supported by a journal bearing which is integrated with a spherical SFD. In this diagram, the journal bearing housing is separated from the main body of the machine by a clearance between the inner sphere (on the body) and the outer sphere (on the housing of the journal bearing). This gap is filled with lubricating oil to act as a shock absorber. The bearing housing is suspended on an elastic structure (centering/retainer spring). The two side ends of the damper are unsealed.

The equation of motion for the system depicted in Fig. 2 can be written as follows:

$$
\begin{aligned}
& M q+K q=\left(\begin{array}{c}
f_{\mathrm{b}}^{(x)} \\
f_{\mathrm{b}}^{(y)} \\
-f_{\mathrm{b}}^{(x)} \\
-f_{\mathrm{b}}^{(y)}
\end{array}\right)+\left(\begin{array}{c}
0 \\
0 \\
f_{\mathrm{d}}^{(x)} \\
f_{\mathrm{d}}^{(y)}
\end{array}\right)+\left(\begin{array}{c}
0 \\
S_{\mathrm{t}} \\
0 \\
S_{\mathrm{g}}
\end{array}\right) \\
& M=\left[\begin{array}{cccc}
m_{\mathrm{t}} & 0 & m_{\mathrm{t}} & 0 \\
0 & m_{\mathrm{t}} & 0 & m_{\mathrm{t}} \\
0 & 0 & m_{\mathrm{g}} & 0 \\
0 & 0 & 0 & m_{\mathrm{g}}
\end{array}\right] \\
& K=\left[\begin{array}{llll}
0 & 0 & 0 & 0 \\
0 & 0 & 0 & 0 \\
0 & 0 & k_{\mathrm{g}} & 0 \\
0 & 0 & 0 & k_{\mathrm{g}}
\end{array}\right] \\
& q=\left[\begin{array}{l}
x_{\mathrm{r}} \\
y_{\mathrm{r}} \\
x_{\mathrm{g}} \\
y_{\mathrm{g}}
\end{array}\right)
\end{aligned}
$$

in which $x_{\mathrm{r}}=x_{\mathrm{t}}-x_{\mathrm{g}}$ and $y_{\mathrm{r}}=y_{\mathrm{t}}-y_{\mathrm{g}}$ the displacements of the shaft center relative to the center of the bearing housing; $x_{\mathrm{g}}$ and $y_{\mathrm{g}}$ are the displacements of the bearing housing center relative to the center of the SFD housing; $m_{\mathrm{g}}$ is the mass of the journal bearing housing; $k_{\mathrm{g}}$ is the effective stiffness of the centering springs that support the SFD; $S_{\mathrm{g}}=g m_{\mathrm{g}}$ is the gravitational force acting on the SFD housing; $f_{\mathrm{d}}^{(x)}$ and $f_{\mathrm{d}}^{(y)}$ the reaction forces from the SFD oil film acting on the bearing housing in the $x$ and $y$ directions, respectively (see 2.3 ).

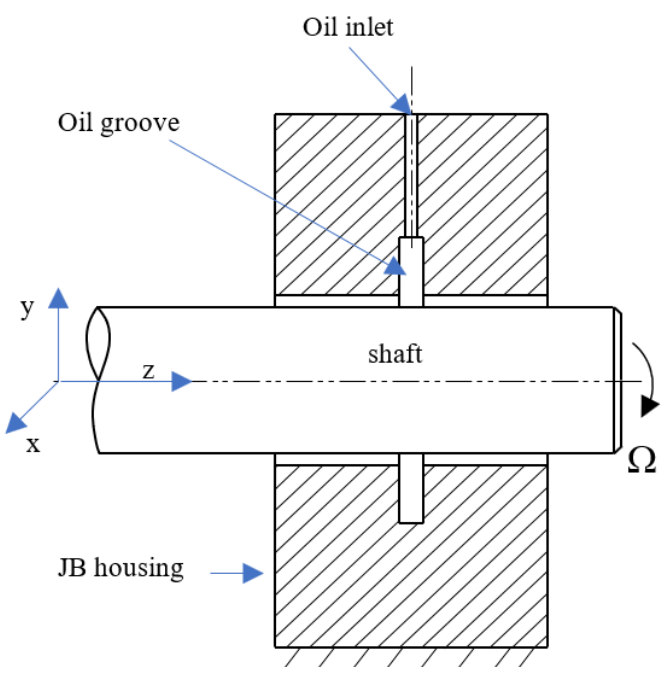

Fig. 1. Shaft-journal bearing diagram

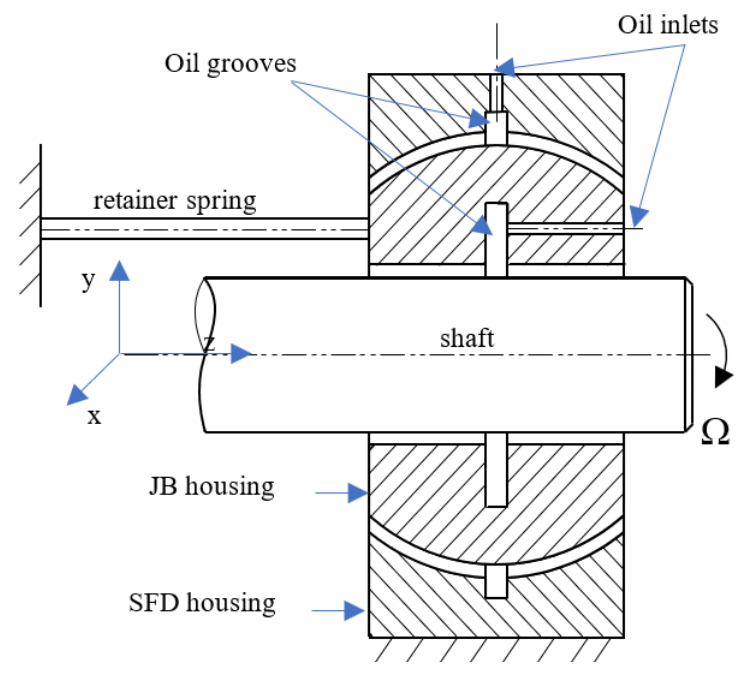

Fig. 2. Shaft-journal bearing-spherical SFD diagram

\subsection{Calculation of Oil Film Forces}

The Reynolds equation governing the pressure distribution within the spherical SFD incompressible oil film (Fig. 3) can be written as follows [10]:

$$
\begin{aligned}
& \frac{\partial}{\partial \theta}\left(\bar{h}_{\mathrm{d}}^{3} \frac{\partial p_{\mathrm{d}}}{\partial \theta}\right)+\cos \beta \frac{\partial}{\partial \beta}\left(\bar{h}_{\mathrm{d}}^{3} \cos \beta \frac{\partial p_{\mathrm{d}}}{\partial \beta}\right) \\
& =12 \mu\left(\frac{R_{\mathrm{d}}}{c_{\mathrm{d}}}\right)^{2} \cos ^{2} \beta \frac{\partial}{\partial t}\left(\bar{h}_{\mathrm{d}}\right)
\end{aligned}
$$




$$
\begin{aligned}
& \bar{h}_{\mathrm{d}}=1-\left(\varepsilon_{\mathrm{d}}^{(\mathrm{x})} \cos \theta+\varepsilon_{\mathrm{d}}^{(\mathrm{y})} \sin \theta\right) \cos \beta \\
& \varepsilon_{\mathrm{d}}^{(\mathrm{x})}=\frac{x_{\mathrm{g}}}{c_{\mathrm{d}}}, \varepsilon_{\mathrm{d}}^{(\mathrm{y})}=\frac{y_{\mathrm{g}}}{c_{\mathrm{d}}}
\end{aligned}
$$

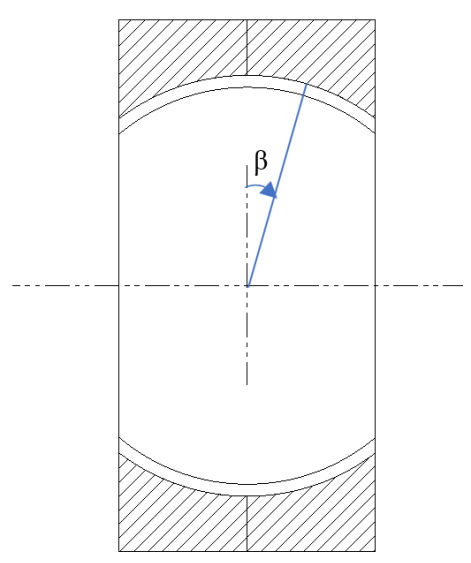

Fig. 3. A schematic diagram of a spherical SFD

The Reynolds equation governing the pressure distribution in the oil film of a conventional journal bearing (Fig. 1 and Fig. 2) can be written as follows [10]:

$$
\begin{aligned}
& \frac{\partial}{\partial \theta}\left(\bar{h}_{\mathrm{b}}^{3} \frac{\partial p_{\mathrm{b}}}{\partial \theta}\right)+\frac{\partial}{\partial \zeta}\left(\bar{h}_{\mathrm{b}}^{3} \frac{\partial p_{\mathrm{b}}}{\partial \zeta}\right) \\
& =12 \mu\left(\frac{R_{\mathrm{b}}}{c_{\mathrm{b}}}\right)^{2}\left(\frac{\partial \bar{h}_{\mathrm{b}}}{\partial t}+\Omega \frac{\partial \bar{h}_{\mathrm{b}}}{\partial \theta}\right) \\
& \zeta=\frac{z_{\mathrm{b}}}{R_{\mathrm{b}}} \\
& \bar{h}_{\mathrm{b}}=1-\varepsilon_{\mathrm{b}}^{(\mathrm{x})} \cos \theta-\varepsilon_{\mathrm{b}}^{(\mathrm{y})} \sin \theta \\
& \varepsilon_{\mathrm{b}}^{(\mathrm{x})}=\frac{x_{\mathrm{r}}}{c_{\mathrm{b}}}, \varepsilon_{\mathrm{b}}^{(\mathrm{y})}=\frac{y_{\mathrm{r}}}{c_{\mathrm{b}}}
\end{aligned}
$$

in which:

- $\quad p_{\mathrm{b}}$ and $p_{\mathrm{d}}$ are oil film pressure in the journal bearing and the SFD, respectively.

- $\quad c_{\mathrm{b}}$ and $c_{\mathrm{d}}$ are the radial clearance of the journal bearing and the SFD, respectively.

- $\quad \mu$ is the dynamic viscosity of the lubricating oil.

- $\Omega$ is the rotational speed of the shaft.

Equations (6) and (9) are discretised over the bearing lands using a central finite difference scheme. After that, the pressure distributions in the journal bearing and in the damper are adapted with the cavitation condition, as follows:

$$
p^{(t)}=\left\{\begin{array}{c}
p \text { if } p>p_{\text {cav }} \\
p_{\text {cav }} \text { if } p \leq p_{\text {cav }}
\end{array}\right\}
$$

with $p_{\text {cav }}$ being the cavitation pressure of the oil film.

With the calculated pressure obtained from formula (13), the reactions at the oil films are integrated over the bearing surfaces as follows:

$$
\begin{aligned}
& \left(\begin{array}{c}
f_{\mathrm{d}}^{(x)} \\
f_{\mathrm{d}}^{(y)}
\end{array}\right)=-n_{\mathrm{L}} R_{\mathrm{d}}^{2} \int_{\beta_{\text {min }}}^{\beta_{\max } 2 \pi} \int_{0}^{2 \pi} p_{\mathrm{d}}^{(t)}\left(\begin{array}{c}
\cos \theta \\
\sin \theta
\end{array}\right) \cos \beta d \theta d \beta \\
& \left(\begin{array}{c}
f_{\mathrm{b}}^{(x)} \\
f_{\mathrm{b}}^{(y)}
\end{array}\right)=-n_{\mathrm{L}} R_{\mathrm{b}}^{2} \int_{\zeta_{\min }}^{\zeta_{\max } 2 \pi} \int_{0}^{2 \pi} p_{\mathrm{b}}^{(t)}\left(\begin{array}{c}
\cos \theta \\
\sin \theta
\end{array}\right) d \theta d \zeta
\end{aligned}
$$

\subsection{Static Equilibrium and Self-Excited Vibrations}

In this paper, to evaluate the efficiency of SFD in reducing vibration of the shaft, shaft unbalance is not considered. The whole system is now not subjected to external stimulation and reaches equilibrium at each speed in a certain range, presumably. In these static equilibrium states, there is no movement at the center of the shaft journal and the bearing housing, therefore:

$$
\begin{aligned}
& q=0 \\
& \dot{q}=0
\end{aligned}
$$

Combining (16), (17) with (1) and (2), the locations of the center of the shaft journal $\left(x_{t}, y_{t}\right)$ and the center of the bearing housing $\left(x_{g}, y_{g}\right)$ can be determined by:

$$
\begin{aligned}
& \left(\begin{array}{c}
f_{b}^{(x)} \\
f_{b}^{(y)}
\end{array}\right)+\left(\begin{array}{c}
0 \\
S_{t}
\end{array}\right)=0 \\
& \left(\begin{array}{c}
f_{b}^{(x)} \\
f_{b}^{(y)} \\
-f_{b}^{(x)} \\
-f_{b}^{(y)}
\end{array}\right)+\left(\begin{array}{c}
0 \\
0 \\
f_{d}^{(x)} \\
f_{d}^{(y)}
\end{array}\right)+\left(\begin{array}{c}
0 \\
S_{t} \\
0 \\
S_{g}
\end{array}\right)-K q=0
\end{aligned}
$$
as follows:

The Jacobian matrices of the systems are defined

1) For the system without SFD:

$$
\begin{aligned}
& J_{1}=\left[\begin{array}{cc}
{[0]_{2 \times 2}} & I_{2 \times 2} \\
\frac{\partial}{\partial s}\left(\begin{array}{l}
f_{b}^{(x)} \\
f_{b}^{(y)}
\end{array}\right) & \frac{\partial}{\partial \dot{s}}\left(\begin{array}{c}
f_{b}^{(x)} \\
f_{b}^{(y)}
\end{array}\right)
\end{array}\right]_{4 \times 4} \\
& \text { with } s=\left[x_{g}, y_{g}\right]^{T}
\end{aligned}
$$

2) For the system with SFD: 


$$
J_{2}=\left[\begin{array}{cc}
{[0]_{4 \times 4}} & I_{4 \times 4} \\
\frac{\partial f}{\partial u} & \frac{\partial f}{\partial \dot{u}}
\end{array}\right]_{8 \times 8}
$$

in which

$$
f=\left(\begin{array}{c}
f_{b}^{(x)} \\
f_{b}^{(y)} \\
f_{d}^{(x)}-f_{b}^{(x)} \\
f_{d}^{(y)}-f_{b}^{(y)}
\end{array}\right) \quad \text { and } u=\left[x_{t}, y_{t}, x_{g}, y_{g}\right]^{T}
$$

According to the theory of dynamical non-linear systems, the static equilibrium states exist only if none of the eigenvalues of the Jacobian matrices (20) and (21) has a positive real part [13]. When this condition is not satisfied, the equilibrium states become unstable and the shaft starts vibrating even with no external source of excitation. The following parts of this paper will investigate the range of the rotational speeds in which the stability of the shaft center is maintained.

\section{Simulation and Discussions}

Equations (1) and (2) are integrated with the time domain to obtain the responses of the state variables using the ode $23 s^{\odot}$ solver, a Rosenbrock-type scheme for stiff ordinary differential equations [11], provided

Table 1. Parameters of systems for simulation by Matlab ${ }^{\circledR}[12]$. The Jacobian matrices (20) and (21) are approximated numerically [12].

The bearing and damper are supplied with oil at a pressure of $p_{\mathrm{s}}=10000 \mathrm{~Pa}$ at the inlet. Due to the deep grooves, the oil pressures in the bearing and the damper at the groove edges are assumed to be constant and equal to $p_{\mathrm{s}}$. Since the oil is supplied sufficiently and continuously, the cavitation pressure in the oil film is now assumed to be the absolute zero pressure.

The finite difference grids and the boundary conditions for the pressure meshes in journal bearing and the SFD are shown in Fig.s $4 \mathrm{a}$ and $4 \mathrm{~b}$. The size of the grids are chosen as $N_{\theta}=51, N_{\beta}=N_{\zeta}=13$. The reaction forces of the oil films are integrated numerically using Simpson's rule. Other system parameters are listed in Table 1.

Fig. 5 shows the transition from static equilibria to unstable states in two cases: with SFD (square) and without SFD (dot). At each rotational speed, the equation (8) is solved using a Newton-Raphson technique to obtain the presumably stable static equilibria for both systems. For each equilibrium state, the Jacobian matrices (9) and (10) are computed numerically and, from which, the real parts of the leading eigenvalues are extracted.

\begin{tabular}{llll}
\hline Parameters & Nomenclature & Value & Unit of measurement \\
\hline Radial of the shaft journal & $R_{\mathrm{b}}$ & 15 & $\mathrm{~mm}$ \\
Radial clearance of the journal bearing & $c_{\mathrm{b}}$ & 0.15 & $\mathrm{~mm}$ \\
Radial of the spherical SFD & $R_{\mathrm{d}}$ & 45 & $\mathrm{~mm}$ \\
Radial clearance of the spherical SFD & $c_{\mathrm{d}}$ & 0.1 & $\mathrm{~mm}$ \\
Axial half bearing length & $L$ & 15 & $\mathrm{~mm}$ \\
$\begin{array}{l}\text { Dynamic viscosity of the lubricating oil } \\
\text { Effective mass of the rotor }\end{array}$ & $\mu$ & 0.005 & $\mathrm{~kg} /(\mathrm{m} . \mathrm{s})$ \\
Effective stiffness of the centering spring & $m_{\mathrm{t}}$ & 3.9 & $\mathrm{~kg}$ \\
Mass of the journal bearing housing & $k_{\mathrm{g}}$ & 600000 & $\mathrm{~N} / \mathrm{m}$ \\
Number of bearing lands & $m_{\mathrm{g}}$ & 1 & $\mathrm{Kg}$ \\
\hline
\end{tabular}

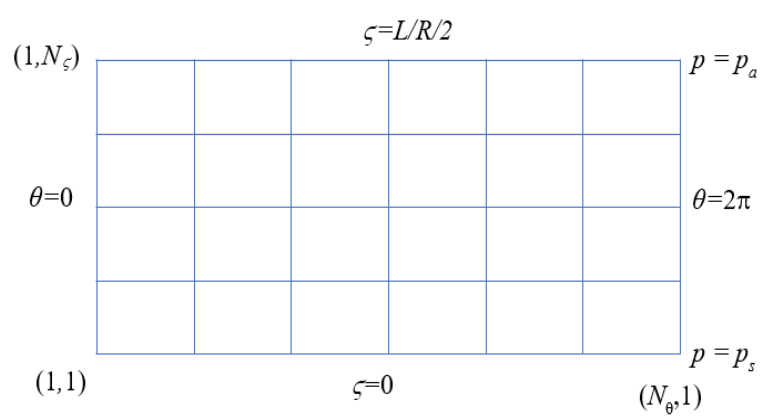

(a)

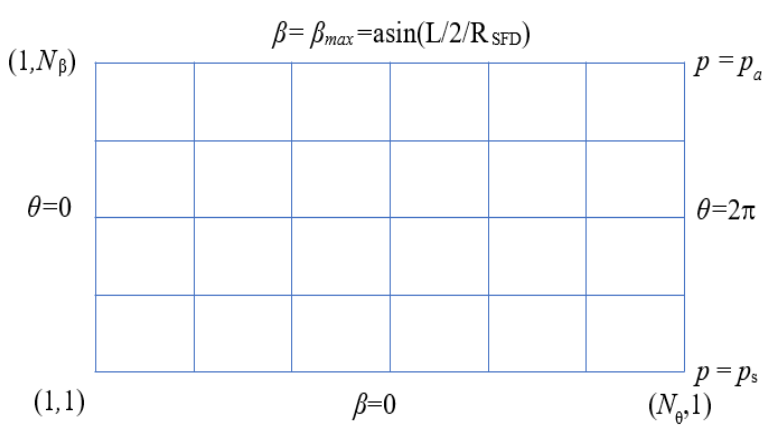

(b)

Fig. 4. FD grids and the boundary conditions 


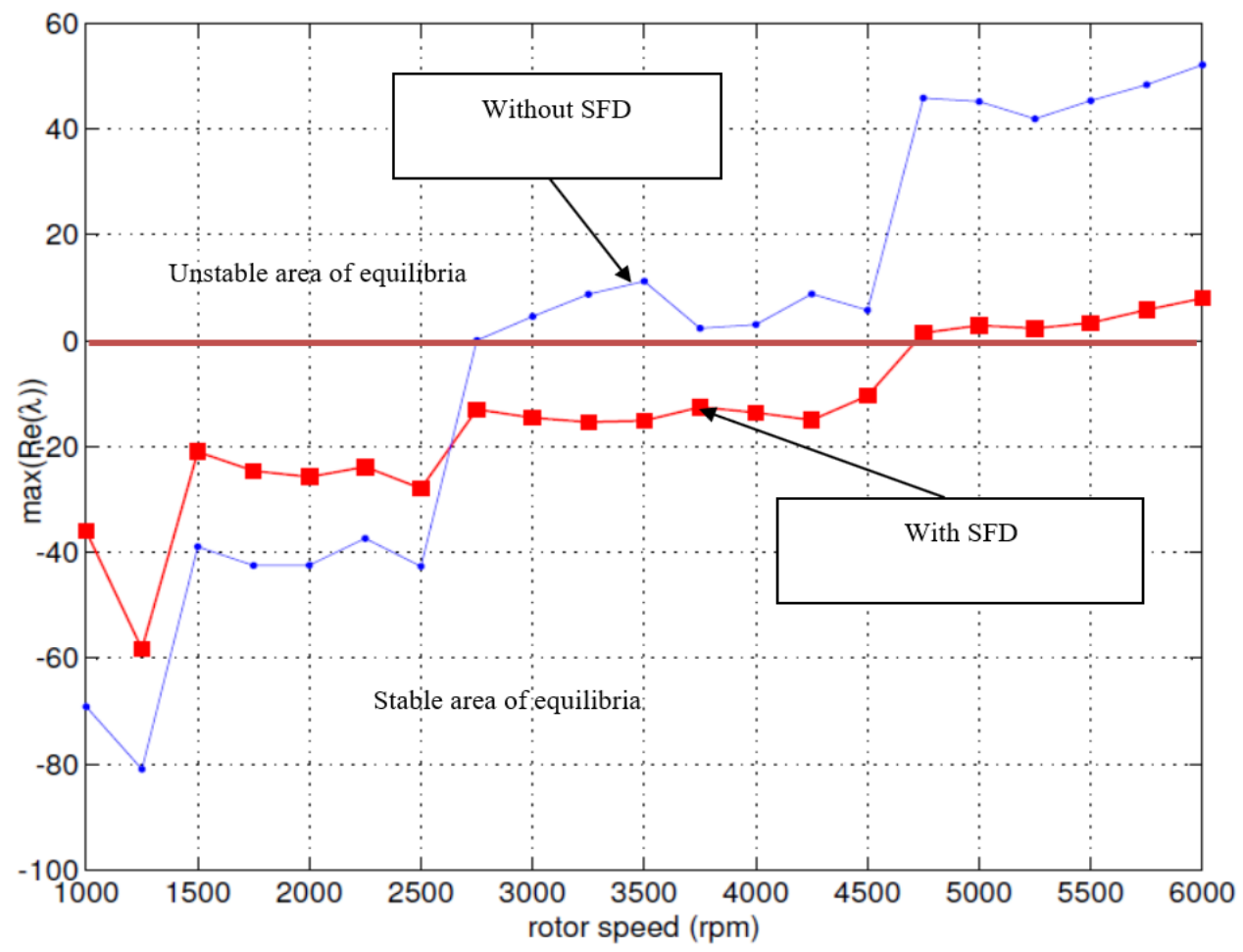

Fig. 5. The stability of the static equilibria

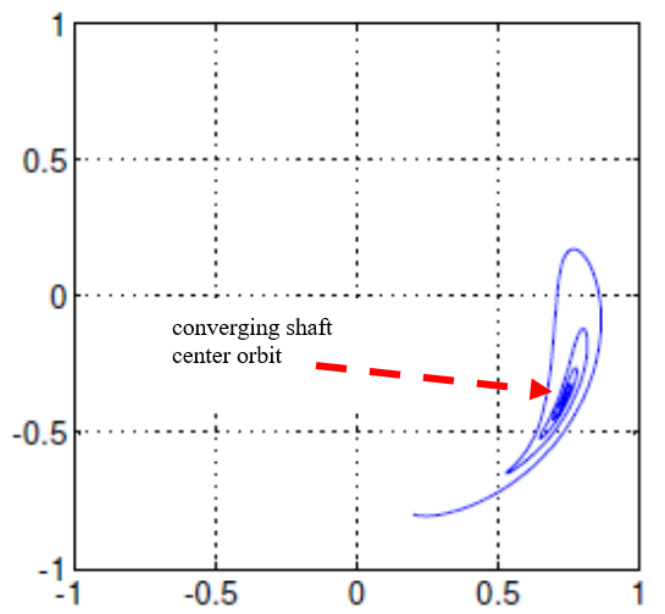

Fig. 6. Shaft orbits of system with no SFD at $2500 \mathrm{rpm}$ (stable)

It can be seen very clearly that the integration of SFD into a journal bearing leads to an expanded stable working range of the shaft speeds, from $2500 \mathrm{rpm}$ to about $4500 \mathrm{rpm}$. The stability is verified in Fig. 6 and 7 with the solutions of equation (1) found in the time domain for the rotational speeds immediately before and after the dynamics of the systems being transformed.

Fig. 6 shows the stability of the shaft center with numerical simulation results showing that the orbit

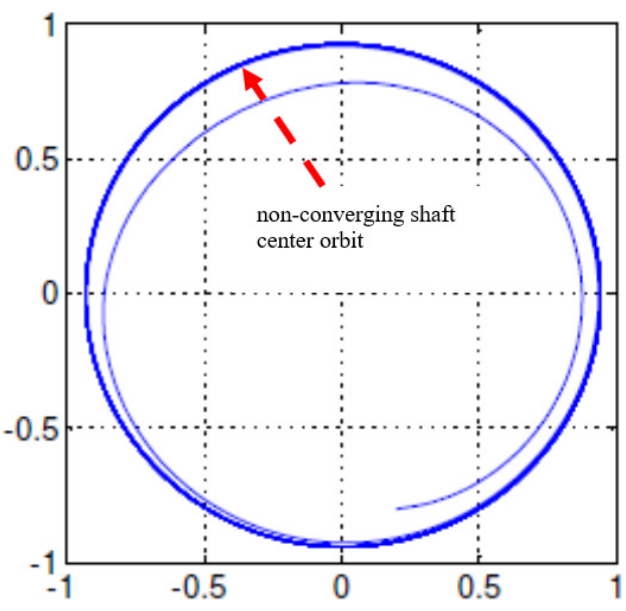

Fig. 7. Shaft orbits of system with no SFD at $3200 \mathrm{rpm}$ (unstable)

converges to a point. Meanwhile, in the dynamic steady state, at $3200 \mathrm{rpm}$ (Fig. 7), the static equilibrium in the bearing-bearing system is proved to be unstable and then, the shaft center orbit becomes a closed loop.

Fig. 8 shows the trajectory of the shaft center for the system with integrated spherical SFD at speeds of $4500 \mathrm{rpm}$ and $5000 \mathrm{rpm}$. The changes in position of the shaft centers in Fig. 8a and 8b fully correlate with the graphs shown in Fig. 5. 


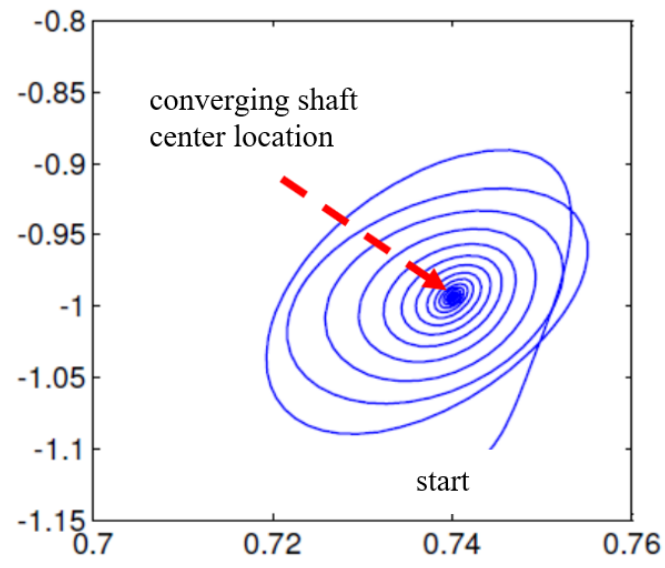

(a)

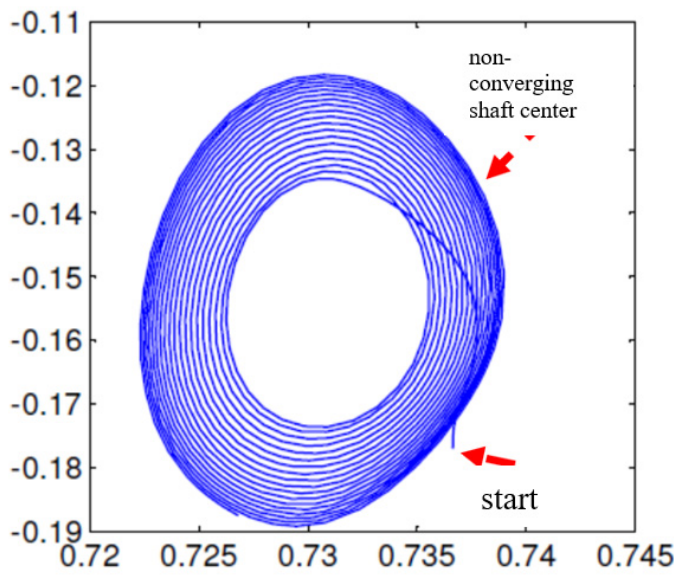

(b)

Fig. 8. Shaft orbit in system with SFD at speeds (a) $4500 \mathrm{rpm}$ (stable); (b) $5000 \mathrm{rpm}$ (unstable)

Fig. 9 is a comparison of the absolute trajectory of the shaft center at $5000 \mathrm{rpm}$. The results showed that the SFD damping had the effect of reducing the vibration amplitude of the shaft many times compared to the case without SFDs.

Fig. 10 provides a closer view of the orbit of shaft center for the case with SFD. The self-excited vibration still pertains, similar to the case without SFD, but with a much reduced amplitude. This can be understood as the extra damping effect that the SFD provides an added capacity to dissipate the vibrational energy.

\section{Conclusion}

The paper has proposed a possibility of incorporating SFD into the journal bearings for rotor systems. The results show the great influence of SFDs in reducing the vibration of the shaft in particular and the whole machine in general. With further investigation of the influences of different parameters of the system, the results of this paper can serve as a basis for studying and applying SFDs to bearing structures to prevent vibration and reduce noise in general and submarines in particular.

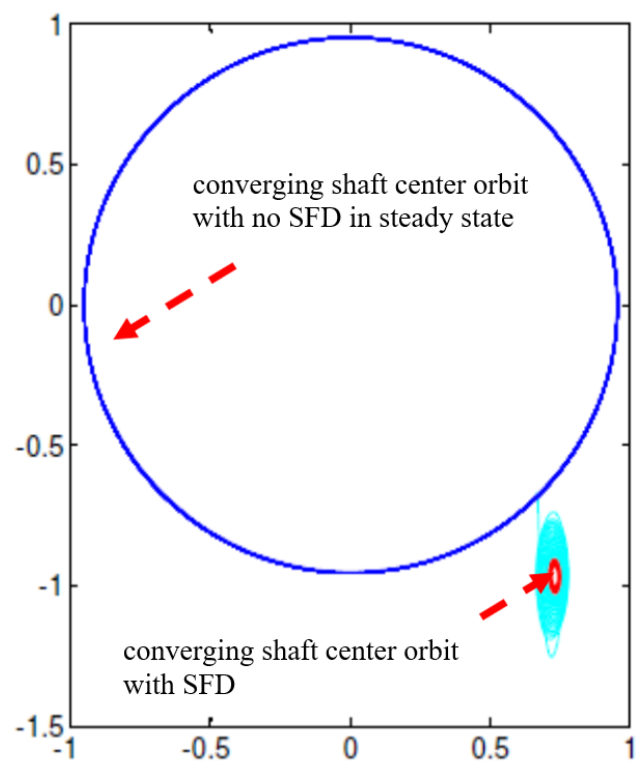

Fig. 9. Limit cycle of systems at $5000 \mathrm{rpm}$.

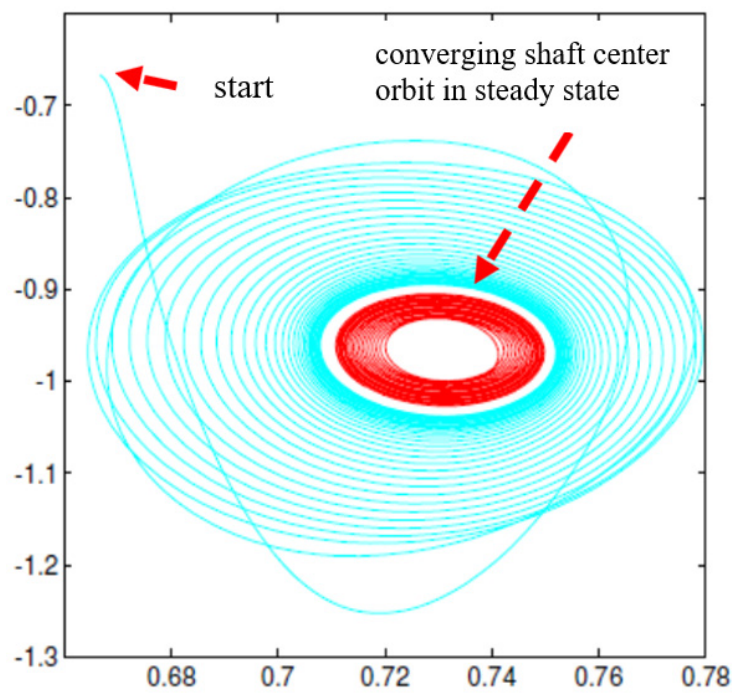

Fig. 10. Shaft trajectory in the presence of SFD

\section{Acknowledgement}

This research has been supported by Hanoi University of Science and Technology via project No. T2015-212.

\section{References}

[1] M. Bos and S. Ryhon, Rolling element bearing provided with a squeeze film damper, Patent No. EP1170520, 2002.

[2] Martin D. Maier, Self-centering squeeze film damper bearing, Patent No. USOO5215384A, 1993.

[3] Helko Schmidt, Muhlhausen (DE), Squeeze film damper, Patent No. US008956048B2, 2015.

[4] R. Holmes and M. Dogan, The performance of a sealed squeeze film bearing in a flexible support structure, 
Proceedings of the Institution of Mechanical Engineers, 1985, Vol. 199(C1), pp. 1-9.

https://doi.org/10.1243/PIME_PROC_1985_199_084_ 02

[5] M.M. Dede, M. Dogan and R. Holmes, The damping capacity of a sealed squeeze film bearing, Transaction of the ASME: Journal of Tribology, 1985, Vol.107, pp. 411-418. https://doi.org/10.1115/1.3261097

[6] P. Bonello, M.J. Brennan and R. Holmes, Non-linear modelling of rotor dynamic systems with squeeze film dampers-efficient integrated approach, Journal of Sound and Vibration, 2002, Vol. 249(4), pp. 743-773. https://doi.org/10.1006/jsvi.2001.3911

[7] P.M. Hai and P. Bonello, An impulsive receptance technique for the time domain computation of the vibration of a whole aero-engine model with nonlinear bearings, Journal of Sound and Vibration, 2008, Vol.318(3), pp. 592-605. https://doi.org/10.1016/j.jsv.2008.04.033

[8] Erik Lind, Magnus Meijer. Simulation and Control of Submarines. M.Sc. thesis, Department of Automatic Control, Lund University, Sweden, 2014.
[9] Wei Cheng, Zhousuo Zhang, and Zhengjia He. Vibration analysis of a submarine model based on an improved ica approach, Adv. in Neural Network Research \& Appli., LNEE 67, pp. 721-728. https://doi.org/10.1007/978-3-642-12990-2_84

[10] C. H. T. Pan. Gas lubricated spherical bearings. Journal of Basic Engineering. 1963 / 311-322. https://doi.org/10.1115/1.3656586

[11] E. Hairer and G. Wanner, Solving ordinary differential equations II: stiff and differential-algebraic problems, $2^{\text {nd }}$ ed. Berlin, Germany: Springer-Verlag, 2002, ch. IV, pp.18-238

[12] L.F. Shampine, M.W. Reichelt, The matlab ODE suite, SIAM Journal on Scientific Computing, 1997, Vol. 18(1), pp.1-22. https://doi.org/10.1137/S1064827594276424

[13] Rudiger Seydel, Practical bifurcation and stability analysis, Interdisciplinary Applied Mathematics, $3^{\text {rd }}$ ed. vol 5. $2^{\text {nd }}$ ed. New York, NY, USA, Germany: Springer, 2010, sec. 1.2 , pp.8-26 